\title{
NOTAS SOBRE O PASSADO COMPOSTO EM PORTUGUÊS *
}

Rodolfo Ilari $^{* *}$

\section{Intuições compartilhadas}

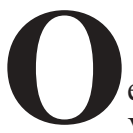

acordo sobre a interpretação do PASSADO COMPOSTO português é quase total. Houve a respeito uma célebre polêmica entre Gonçalves

Viana (que escreveu no final do século XIX) e Paiva Boléo (cujo principal texto é da década de 1930), mas que nasceu a meu ver da dificuldade de resumir o sentido do passado composto numa única palavra. Para Gonçalves Viana, essa palavra era "repetição"; Boléo reconheceu a necessidade de considerar também uma interpretação durativa. Tentativas de generalização à parte, os fatos lembrados e as interpretações propostas são os mesmos. Assim, paradoxalmente, é possível concordar com ambos os autores, retomando deles uma análise ainda hoje válida, que resumo nos pontos a seguir:

1. O PASSADO COMPOSTO português exprime iteração, cf.

(1) Ele tem-nos visitado várias vezes / * uma vez.

* Uma primeira versão deste trabalho foi apresentada durante conferência em Budapest e publicada nos Anais daquele congresso.

** Universidade Estadual de Campinas 
2. exprime iteração independentemente de estar presente na oração um advérbio indicando frequiência:

(2) Ele nos visitou. ( = uma vez ou várias vezes)

(3) Ele nos visitou várias vezes. (= várias vezes)

(4) Ele nos tem visitado. (= mais de uma vez)

3. assume eventualmente um valor de continuidade:

(5) Tenho estado doente.

4. diz respeito a um período que começa no passado mas não se conclui no passado:

(6) Le Monde tem sido entregue em São Paulo pelo correio aéreo desde 1927. / * desde 1927 até 1968.

A essas observações de Viana e Boléo, podemos acrescentar outras, que eles não fizeram, ou por serem óbvias (dispensando por isso mesmo os comentários de uma gramática de tipo "tradicional") ou por exigirem conceitos ainda não disponíveis em suas épocas:

5. a distinção de um valor durativo e um valor iterativo tem a ver com características aspectuais do predicado, sendo relevante a Aktionsart do verbo:

(7) O Fernando tem publicado na série "Novos Escritores" da Editora Ática.

(8) A este governo tem faltado vontade política para a solução dos problemas.

6. o PASSADO COMPOSTO é inadequado não só para descrever fatos que ocorreram uma única vez, mas ainda para descrever a repetição, se se quer ao mesmo tempo explicitar quantas vezes o fato se repetiu:

(9) * Eles têm vindo três vezes (cf. fr. Ils sont venus trois fois, it. Sono venuti tre volte).

(10) Eles têm vindo muitas vezes / milhares de vezes. 
7. a interpretação e a gramaticalidade de orações no PASSADO COMPOSTO são afetadas pela quantificação dos sintagmas nominais presentes na sentença, e pela ocorrência de adjuntos :

(11) O surto de meningite tem matado muita gente.

(12) * O surto de meningite tem matado uma pessoa / * ... a zeladora.

(13) * O surto de meningite tem matado Pedro, Carlos e José.

(14) O surto de meningite tem matado uma pessoa a cada três horas, nesta cidade.

Provavelmente, o que sabemos hoje do PASSADO COMPOSTO está longe de esgotar a complexidade semântica dessa forma; assim, a presente exposição poderia ter sido orientada no sentido de buscar mais dados. Seguirei um outro caminho - o de perguntar o que é necessário para reconstituir formalmente as intuições disponíveis.

\section{O tratamento dos tempos / o passado}

Para tratar do tempo, os semanticistas de formação lógica têm lançado mão de vários dispositivos formais, igualmente eficazes do ponto de vista técnico, mas às vezes "filosoficamente" distintos na medida em que remetem a "ontologias" diferentes ou refletem diferentes concepções de semântica. Tomarei como referência o tratamento que Richard Montague propõe para o Present Perfect do Inglês no Proper Treatment of Quantification. Montague só analisou em sua obra uma parte muito pequena das construções do inglês; dadas as dimensões minúsculas dessa amostra, é surpreendente que ele tenha tratado o tempo inglês que, por sua estrutura morfológica, é o análogo do nosso passado composto, o Present Perfect. As regras de que ele escreve recebem em seu trabalho os números $\mathrm{S}_{17}$ e $\mathrm{T}_{17}$, e são, respectivamente, uma regra sintática destinada a dar conta da "morfologia" das sentenças no Present Perfect e uma regra "de tradução" que constrói as fórmulas correspondentes de $I L$, a Linguagem Intensional em que Montague formula o sentido das sentenças do inglês, sem incorrer nas ambigüidades próprias de uma língua natural. Transcrevo essas regras que em princípio deveriam permitir a construção de fórmulas de uma linguagem lógica capaz de exibir todas as propriedades significativas das sentenças inglesas no Present Perfect. 
$\left(\mathrm{S}_{17}\right)$ PRESENT PERFECT: Se $\alpha \in \mathrm{P}_{\mathrm{T}}$ e $\delta \in \mathrm{P}_{\mathrm{IV}}$, então $\mathrm{F}_{14}(\alpha, \delta) \in \mathrm{P}_{\mathrm{t}}$ onde $\mathrm{F}_{14}(\alpha, \delta)$ é o resultado de escrever o primeiro verbo em $\delta$ em sua forma de present perfect, terceira pessoa do singular; entenda-se ademais que $\mathrm{P}_{T}, \mathrm{P}_{\text {IV }}$ e $\mathrm{P}_{\mathrm{t}}$ são maneiras de denominar as categorias dos sintagmas nominais, dos sintagmas verbais e das orações; e $\mathrm{F}_{14}$ denota o décimo quarto modo de composição de expressões, dentre os que a sintaxe torna disponíveis nesse nível;

\section{$\left(\mathrm{T}_{17}\right)$ PRESENT PERFECT: $\mathrm{F}_{14}(\alpha, \delta)$ traduz-se $\mathrm{P} \alpha^{\prime}\left({ }^{\wedge} \delta^{\prime}\right)$}

Através da regra $\left(\mathrm{S}_{17}\right)$, Montague caracteriza o PRESENT PERFECT como uma das maneiras de "juntar sujeito e predicado formando uma sentença"; $\mathrm{T}_{17}$ atribui ao operador de passado o escopo mais amplo possível, ou seja, a’ $\left({ }^{\wedge} \delta\right.$ ' ) fica no escopo de P.

Lembremos que o PTQ proporciona dois "métodos" para combinar o sujeito com o predicado dando origem a uma sentença: o primeiro consiste em combiná-los diretamente, ilustrado pelo exemplo (15):

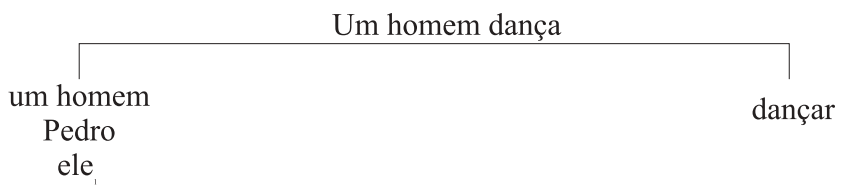

O segundo método consiste em usar a expressão nominal (Pedro, um homem, todo habitante de Campinas) em posição inicial de oração, como substituto de um pronome indexado, presente numa fórmula gerada, por exemplo, pelo primeiro método, como na árvore (16):

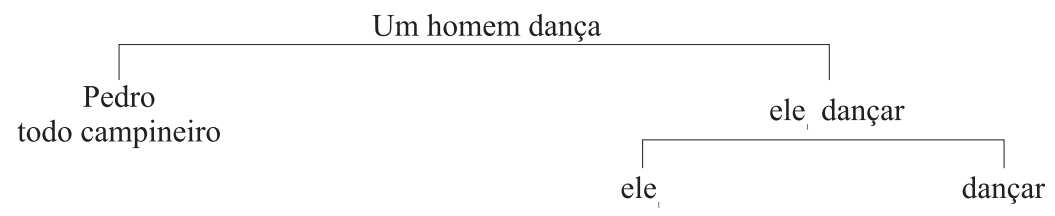


Esse segundo método, que nada mais é do que a ligação de variáveis da lógica elementar, dá conta de uma série de casos de correferência; por meio dele, por exemplo, se obtém a representação correta de sentenças como "Todo vaidoso se promove", "Um homem canta e dança”, que não significam, obviamente, "todo vaidoso promove todo vaidoso" nem "um homem canta e um homem dança".

Definindo a regra que constrói orações negativas como uma regra que cria sentenças, e dispondo para ligar sujeitos e predicados dos dois métodos descritos em (15) e (16), ganha-se a possibilidade de visualizar mediante representações diferentes, (18 a) e (18 b), a ambigüidade de sentenças como

(17) Todos os atletas não estavam no estádio [na hora da explosão da bomba]

(17) assume ora o sentido de negação da generalização, ora de generalização da negação, uma possibilidade de dúplice leitura que afeta potencialmente todas as sentenças em que a negação interage com a quantificação universal.

(18a)

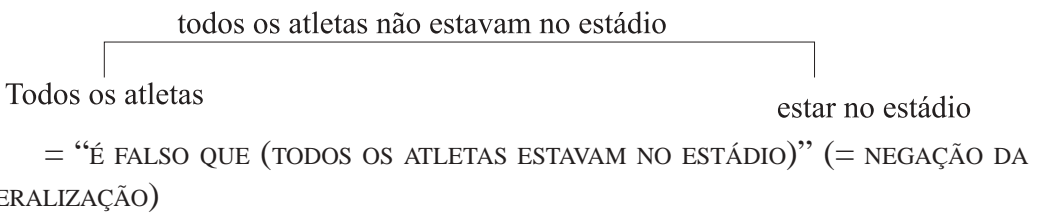

$(18 b)$

todos os atletas não estavam no estádio

Todos os atletas

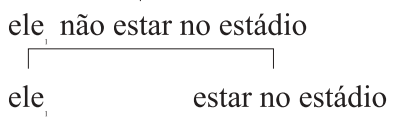

= "VALE PARA TODOS OS ATLETAS, QUE [ELES, NÃO (ESTAVAM NO ESTÁDio)] (= GENERALIZAÇÃO DA NEGAÇÃO)

Ora, a interação dos quantificadores com os operadores temporais gera ambigüidades semelhantes, pois 
(19) Todos os generais já foram soldados rasos.

pode ser entendida como (20) ou como (21)

(20) Já houve um momento em que todos os generais eram soldados rasos.

(21) Para todo general, já houve um momento em que ele era soldado raso.

e

(22) O diretor de publicações sempre foi um lingüista.

tanto pode descrever o atual diretor de publicações (informando que ele nunca abandonou sua profissão de lingüista) como pode expressar uma regularidade observada no recrutamento dos vários diretores de publicações que já existiram. Essas ambigüidades são reais; mostrar no que consistem é um dos méritos da formulação de Montague. Mas é claro que isso não basta, pois a fórmula proposta por Montague para tratar do Present Perfect não dá conta do sentido do PASSADO COMPOSTO português, tal como vem sendo caracterizado desde Viana e Boléo, a menos que passe por modificações radicais. Na sequiência, aponto informalmente para algumas dessas modificações.

\section{Determinações semânticas na interpretação do passado composto}

\section{"O passado composto português exprime iteração"}

Afirmar que "Pedro tem visitado Maceió" é afirmar, entre outros, que as visitas de Pedro a Maceió se repetiram no passado. Mal comparando, há uma proporcionalidade entre singular e plural dos nomes, de um lado, e passado simples e composto dos verbos de ação, de outro. Em ambos os pares há um elemento "não marcado": no caso dos nomes, trata-se do singular, que pode referir-se a um ou mais objetos; no caso dos tempos verbais, trata-se do passado simples, que registra um fato singular ou um fato repetido. Essa observação ajuda a compreender por que (23) decorre tanto de (24) como de (25), mostran- 
do que essas duas orações, cada uma a seu modo, referem-se a eventos "plurais":

(23) Houve várias reclamações de telespectadores contra a violência da nova série policial.

(24) Vários telespectadores reclamaram...

(25) Vários telespectadores têm reclamado...

Mas (24) e (25) não são sinônimas: somente (24) poderia ser utilizada no dia seguinte ao lançamento da nova série policial para relatar uma reação coletiva da audiência. Para entender a peculiaridade semântica do PASSADO COMPOSTO, é preciso entender pluralização como um "escalonamento de eventos no tempo". Em outras palavras, se interpretarmos (26) por referência à sentença "Pedro visita Maceió" e às diferentes histórias relatadas em (27), teremos que considerá-la verdadeira somente nos mundos I e II :

(26) Pedro tem visitado Maceió.

\begin{tabular}{c|c|c|c|c|c|c|c}
\hline \multicolumn{2}{c}{ "Pedro visita a Maceió" é verdadeira em } \\
\hline & tempo $_{i-6}$ & tempo $_{i-5}$ & tempo $_{i-4}$ & $\begin{array}{c}\text { tempo }_{i-} \\
\text { (tempo }\end{array}$ t-2 & tempo $_{i-1}$ & tempo $_{i}$ \\
\hline mundo I & $\mathrm{V}$ & $\mathrm{F}$ & $\mathrm{V}$ & $\mathrm{F}$ & $\mathrm{V}$ & $\mathrm{F}$ & $\mathrm{V}$ \\
\hline mundo II & $\mathrm{V}$ & $\mathrm{F}$ & $\mathrm{F}$ & $\mathrm{V}$ & $\mathrm{F}$ & $\mathrm{F}$ & $\mathrm{V}$ \\
\hline mundo III & $\mathrm{F}$ & $\mathrm{F}$ & $\mathrm{V}$ & $\mathrm{F}$ & $\mathrm{F}$ & $\mathrm{F}$ & $\mathrm{F}$ \\
\hline mundo IV & $\mathrm{V}$ & $\mathrm{V}$ & $\mathrm{V}$ & $\mathrm{F}$ & $\mathrm{F}$ & $\mathrm{F}$ & $\mathrm{F}$ \\
\hline
\end{tabular}

(O que falta no mundo III é a repetição; o que falta no mundo IV é o "escalonamento ao longo do tempo" dos momentos em que se realiza "Pedro visita Maceió".)

Descontado o problema ilustrado pelo mundo IV do quadro (27), poderíamos pensar que a idéia de escalonamento no tempo capta, no essencial, o que há para ser captado na idéia que repetição desempenha na semântica do PASSADO cOMPOSTO. Não é bem assim. No caso da sentença (26), a fórmula de cuja verdade ou falsidade em momentos anteriores ao momento de fala depende a verdade da sentença no passado é "Pedro visita Maceió". Sendo o sujeito dessa sentença um nome próprio, o modo como ligamos sujeito e predicado nessa sentença (método 1 ou método 2 de Montague) não faz nenhuma diferença para a interpretação. As coisas se passam de modo bem diferente quando o sujeito da sentença é uma expressão quantificada. Para 
(28) Alguns funcionários da Volkswagen têm alugado esta chácara.

a escolha de um ou outro método de construção da relação sujeito - predicado resulta respectivamente nas árvores (29) e (30)

\begin{tabular}{l}
\multicolumn{2}{c}{ Alguns funcionários da V. têm alugado esta chácara } \\
\cline { 2 - 2 } \\
alguns funcionários da V.
\end{tabular}

\begin{tabular}{cl}
\multicolumn{2}{l}{ Alguns funcionários da V. têm alugado esta chácara } \\
\cline { 2 - 3 } \\
alguns funcionários da V.
\end{tabular}

e nas interpretações (31) e (32):

(31) Repete-se de tempos, num período do passado que (alguns funcionários da Volkswagen)

(32) Para alguns funcionários da Volkswagen [repete-se de tempos em tempos num período do passado (que eles alugam esta chácara)].

Confrontando (31) e (32) com os quadros (33) e (34)

\begin{tabular}{c|c|c|c|c|c|c}
\hline nos mundos & $\mathrm{m}_{\mathrm{i}-5}$ & $\mathrm{~m}_{\mathrm{i}-4}$ & $\mathrm{~m}_{\mathrm{i}-3}$ & $\begin{array}{c}\mathrm{M}_{\mathrm{i}-} \\
2\end{array}$ & $\mathrm{~m}_{\mathrm{i}-1}$ & $\mathrm{~m}_{\mathrm{i}}$ \\
\hline $\mathrm{v}\{\mathrm{x}: \mathrm{x}$ aluga a chácara $\}=$ & $\{\mathrm{a}, \mathrm{b}, \mathrm{c}, \mathrm{d}, \mathrm{n}\}$ & $\varnothing$ & $\{\mathrm{b}, \mathrm{c}, \mathrm{d}\}$ & $\varnothing$ & $\{\mathrm{b}, \mathrm{c}, \mathrm{d}, \mathrm{m}\}$ & $\varnothing$ \\
\hline vi $\{\mathrm{x}: \mathrm{x}$ aluga a chácara $\}=$ & $\{\mathrm{a}, \mathrm{b}, \mathrm{c}, \mathrm{d}, \mathrm{n}\}$ & $\varnothing$ & $\{\mathrm{b}, \mathrm{c}, \mathrm{d}, \mathrm{m}, \mathrm{n}, \mathrm{o}, \mathrm{p}\}$ & $\varnothing$ & $\{\mathrm{a}, \mathrm{b}, \mathrm{c}, \mathrm{d}\}$ & $\varnothing$ \\
\hline vii $\{\mathrm{x}: \mathrm{x}$ aluga a chácara $\}=$ & $\{\mathrm{a}, \mathrm{b}, \mathrm{c}\}$ & $\varnothing$ & $\{\mathrm{d}, \mathrm{e}, \mathrm{f}\}$ & $\varnothing$ & $\{\mathrm{g}, \mathrm{h}, \mathrm{i}\}$ & $\varnothing$ \\
\hline
\end{tabular}




\begin{tabular}{c|c|c|c|c|c|c|c|c|c}
\hline nos mundos & $\mathrm{m}_{\mathrm{i}-8}$ & $\mathrm{~m}_{\mathrm{i}-7}$ & $\mathrm{~m}_{\mathrm{i}-6}$ & $\mathrm{~m}_{\mathrm{i}-5}$ & $\mathrm{~m}_{\mathrm{i}-4}$ & $\mathrm{~m}_{\mathrm{i}-3}$ & $\mathrm{~m}_{\mathrm{i}-2}$ & $\mathrm{~m}_{\mathrm{i}-1}$ & $\mathrm{~m}_{\mathrm{i}}$ \\
\hline $\begin{array}{c}\text { viii }\{\mathrm{x}: \mathrm{x} \text { aluga a chácara }\} \\
=\end{array}$ & $\{\mathrm{a}\}$ & $\{\mathrm{b}\}$ & $\{\mathrm{c}\}$ & $\{\mathrm{a}\}$ & $\{\mathrm{b}\}$ & $\{\mathrm{c}\}$ & $\{\mathrm{a}\}$ & $\{\mathrm{b}\}$ & $\{\mathrm{c}\}$ \\
\hline
\end{tabular}

(Cada um dos indivíduos do conjunto \{a,b,c $\}$ realiza ciclicamente a ação de alugar a chácara. Não há um mesmo conjunto de pessoas que aluga a cada vez, nem há a cada vez um novo grupo de indivíduos que aluga)

constatamos que (31) é verdadeira se M for como V,VI ou VII, e que (32) é verdadeira se M for como V, VI ou VII. Fazer essa constatação é o mesmo que admitir que, à luz do PTQ, as sentenças portuguesas com verbo no passado composto e sujeito quantificado são orações ambíguas, e esse é mais um resultado intuitivamente correto, porque de fato não interpretamos da mesma maneira

(35) Semanalmente, algumas pessoas têm sido detidas.

[Contexto: A entrada de imigrantes ilegais no país é cada vez mais difícil...]

(36) Algumas pessoas têm comparecido semanalmente à polícia.

[Contexto: O regime reprime seus opositores obrigando-os a assinar um livro de presença, como uma forma de liberdade vigiada; por causa disso...]

A distinção é entre o que poderíamos chamar de "predicação coletiva" (cada episódio de captura aplica-se a um grupo diferente) e "predicação distributiva" (existe um grupo de indivíduos em liberdade vigiada, cada um dos quais faz a sua visita semanal à polícia, onde assina o livro de presença). Novamente estamos diante de uma regra que traz à tona uma ambigüidade, e isso é positivo. Há, porém, uma outra situação, bem diferente dessas, que se descreve tipicamente em português por meio do PASSADO COMPOSTO, descrita em (37):

\begin{tabular}{l|c|c|c|c|c|c|c|c|c}
\cline { 2 - 9 } & $\mathrm{i}-8$ & $\mathrm{i}-7$ & $\mathrm{i}-6$ & $\mathrm{i}-5$ & $\mathrm{i}-4$ & $\mathrm{i}-3$ & $\mathrm{i}-2$ & $\mathrm{i}-1$ & $\mathrm{i}$ \\
\hline ix $\{\mathrm{x}$ : x aluga a chácara $\}=$ & $\{\mathrm{a}\}$ & $\{\varnothing\}$ & $\{\mathrm{b}\}$ & $\{\varnothing\}$ & $\{\mathrm{c}\}$ & $\{\varnothing\}$ & $\{\mathrm{d}\}$ & $\{\varnothing\}$ & $\{\mathrm{e}\}$ \\
\hline
\end{tabular}

Não há grupos em nenhum momento, nem há identidade dos indivíduos envolvidos na ação. 
Nessa situação, mantém-se a idéia de escalonamento no tempo e de pluralização dos participantes, mas não podemos apontar um grupo de agentes, cada um dos quais se envolve ciclicamente na mesma ação, nem uma série de ações sucessivas envolvendo a cada ocasião uma pluralidade de indivíduos; aqui, o plural do sujeito resulta de que, reunindo vários protagonistas individuais, obtemos um "grupo através do tempo". É a situação que faria sentido associar a

(38) Muitas pessoas têm morrido no Rio [desde que começaram os tiroteios entre traficantes].

No fragmento de gramática que expus, há somente duas maneiras de representar a relação sujeito - predicado: e esta "terceira" interpretação, característica de orações como (38), não é nenhuma delas. Fica clara, portanto, a necessidade de estender a gramática e a extensão a ser tentada poderia ser no sentido de incorporar a proposta de Davidson (1967) sobre a estrutura semântica das sentenças de ação.

Davidson propôs para as sentenças de ação uma análise semântica em que o próprio evento é representado como um dos argumentos do predicado; assim, o predicado assassinar é definido como um predicado de três lugares, correspondentes respectivamente ao assassino, à vítima e ao evento; nessas condições, uma sentença como (39) pode ser traduzida em (40), uma fórmula do cálculo de predicados de primeira ordem, que por sua vez acarreta (41):

(39) Charlotte Corday assassinou Marat no banho com uma faca.

(40) $\exists \mathrm{u}[\mathrm{A}(\mathrm{cmu}) \& \mathrm{EM}(\mathrm{b}, \mathrm{u}) \& \mathrm{COM}(\mathrm{f}, \mathrm{u})]$

[Literalmente: existe um evento que consiste no assassinato de Marat por Ch.Corday e esse evento ocorreu no banho, e teve por instrumento uma faca]

(41) $\exists \mathrm{u} \exists \mathrm{x} A(\mathrm{xmu})$

[Literalmente: existe um evento em que alguém assassina Marat]

Se nos dermos a possibilidade de indicar não só que existe pelo menos um evento do tipo considerado, mas que há uma pluralidade deles que se escalona no tempo, acrescentando um sinal de " $+\mathrm{e}$ " ao quantificador existencial que opera sobre a variável para eventos, chegaremos a fórmulas que captam a idéia de um "grupo através do tempo"; por exemplo, (38) poderá ser traduzida por algo como 
Antes de encerrar estas reflexões sobre iteração de eventos, lembremos porém que nem a quantificação que nos é dada pelo cálculo de predicados de primeira ordem, nem o novo quantificador de escalonamento para eventos que acabo de propor informalmente, esclarecem completamente o caráter iterativo do PASSADO COMPOSTO: resolvida a interação da quantificação do sujeito com o PASSADO COMPOSTO, sobram muitas coisas por explicar sobre o "escalonamento do tempo" que atribuímos intuitivamente àquela perífrase como marca registrada. Uma pergunta é se a noção de reiteração que convém ao passado composto é a mesma que encontramos em outros tempos verbais que indicam ação habitual, e a resposta é não. Além do PASSADO COMPOSTO, também o imperfeito, o presente simples e o presente progressivo falam de fatos que se repetem; mas as agramaticalidades e as diferenças de interpretação que se podem apontar em (43) parecem sugerir que o PASSADO COMPOSTO não serve, por exemplo, para indicar disposição (no sentido dado por Quine 1951):

(43) a . Esta flor é o beijinho. É também conhecida como Maria-semvergonha, porque dá / *tem dado/*está dando em qualquer canto.

b . A água entra/*tem entrado em ebulição aos cem graus.

c . O vulcão da ilha entra / tem entrado em erupção pelo menos uma vez a cada vinte anos.

Uma das coisas sobre as quais pode haver certeza, aliás, é que o escalonamento no tempo que caracteriza o PASSADO COMPOSTO, não precisa ser absolutamente regular:

(44) Alberto tem voltado de Rio Claro no trem das 8h12min.

não se torna falsa se Alberto perdeu o trem algumas vezes ou se, em determinadas ocasiões, optou por outro horário ou por um outro meio de transporte. (44) garante tão somente que, na falta de uma razão melhor, Alberto sempre volta no trem das $8 \mathrm{~h} 12 \mathrm{~min}$, e que é isso que se espera dele. Há, em suma, nessa afirmação, um elemento quantificacional, mas esse elemento é de tipo mais probabilístico do que categórico.

O passado composto é incompatível com os adjuntos que respondem em termos exatos às perguntas "quando?" e "quantas vezes?".

Embora compreensíveis, as sentenças (45) a (48)

(45) * O João tem lido três vezes Guerra e Paz. 
(46) * Esse aluno tem recebido três advertências.

(47) * Tenho feito três viagens a Nova Iorque desde que casei.

(48) * Tenho conhecido três engenheiros químicos em Porto Velho.

são agramaticais. Sua comparação com sentenças de outras línguas em que existe um PASSADO COMPOSTO, como (49) e (50), e com outras sentenças do português plenamente aceitáveis, como (51) e (53), mostra que as primeiras transgridem um princípio pelo qual, em presença de um PASSADO COMPOSTO, o número de vezes que um determinado evento se repete não pode ser explicitado em termos numéricos.

(49) Ingl. John has read three times War and Peace.

(50) Ital. Giovanni ha letto tre volte Guerra e Pace.

(51) Esse aluno tem recebido muitas advertências.

(52) Tenho feito muitas viagens a Nova Iorque.

(53) Tenho conhecido muitos engenheiros químicos em Porto Velho.

Existem, é verdade, exemplos como

(54) O carteiro tem tocado duas vezes.

em que a ocorrência do PASSADO COMPOSTO junto com os numerais cardinais não cria problemas, mas este exemplo é mais complexo. Os dois toques de campainha por meio dos quais o carteiro avisa que há correspondência definem cada um dos episódios em que ele toca, isto é, cada uma de suas visitas. Mas o número exato de visitas fica indeterminado.

À restrição sobre contar os eventos corresponde uma restrição sobre datas: as datas são também incompatíveis com o PASSADO COMPOSTO, a menos que se trate de indicações de calendário passíveis de repetição. Assim, (55) resulta agramatical, ao contrário de (56) 
(55) *Tem chovido no último dia de finados.

(56) Tem chovido no dia de finados.

A partir desses exemplos, torna-se claro que há necessidade de duas formas de inserção para os adjuntos que indicam data e número de vezes que um determinado fato ocorre, pois esses adjuntos são aceitáveis quando caracterizam o episódio internamente, e são rejeitados quando aplicados à série de episódios tomada como um todo. Se analisássemos mais extensamente os adjuntos de tempo que podem ocorrer em sentenças no PASSADO COMPOSTO, veríamos que a necessidade de dupla inserção é confirmada também pelos adjuntos que indicam duração:

(57) Ele tem visitado a família por um mês.

o adjunto de duração "por um mês" só é aceitável porque marca a duração de cada visita: não é pensável que esse adjunto especifique a extensão total de um período no interior do qual várias visitas se sucedem; em (58)

(58) Ele tem vindo toda quinta-feira nos últimos trinta anos. "nos últimos trinta anos" marca precisamente esse período.

\section{PC aponta para um período que, começando no passado, alcança o momento de fala e, eventualmente, o ultrapassa.}

Ao tratar da sentença "Pedro tem visitado Maceió" observei que ela seria declarada falsa numa situação em que as visitas de Pedro a Maceió ocorreram amiudadamente num passado distante, mas não voltaram a repetir-se em momentos mais próximos ao momento de fala. Quando se tenta entender esse fato, vêm à mente algumas análises célebres que já foram feitas sobre os passados compostos de outras línguas, aproximando-os de um modo ou de outro do presente. A mais célebre delas é a que Benveniste dedica ao PASSÉ composé do francês: essa análise deve ser relacionada não só à história dos passados compostos românicos, que indicavam na origem o resultado presente de uma ação passada (esse sentido originário se preserva em sentenças como "Tenho uma casinha alugada"), mas ainda com a distinção que Benveniste estabelece entre discours e histoire: utilizando o PASSÉ COMPOSÉ, um tempo do discurso no senti- 
do benvenisteano, os falantes do francês teriam a possibilidade de caracterizar o fato de que tratam como ainda relevante para o locutor no momento de fala; utilizando o PASSÉ SIMPLE, dariam ao mesmo fato um registro histórico isento de qualquer envolvimento. Essa explicação é altamente sugestiva para o francês, e parece corresponder às motivações distintas que, algumas décadas atrás, orientavam a escolha de duas gerações de franceses entre (59) e (60):

(59) Jean Moulin a été tué par la Gestapo.

\section{(60) Jean Moulin fut tué par la Gestapo.}

a primeira seria escolhida por quem acompanhou de perto os fatos relatados, ao passo que a segunda seria mais provavelmente usada por alguém que leu sobre eles num livro de história.

Basta contudo traduzir essas duas frases, para confirmar que a distinção em português entre passado simples e composto não é essa. Provavelmente, o PASSADO COMPOSTO do português já foi um "passado próximo", mas hoje esse uso se reduz à fórmula "tenho dito", usada para encerrar um discurso, e que, no Brasil, soa pedante ou ridícula - na fala coloquial brasileira é mais provável hoje em dia que as pessoas concluam a fala com um curiosíssimo "falou?" interrogativo, que analisei em outro lugar (Ilari, Godoi e Pires de Oliveira, 1986) como um caso de derivação delocutiva .

O tipo de compromisso que o passado composto mantém com o momento de fala é outro, e fica evidenciado, mais uma vez, pelo contraste com os demais tempos do próprio português. Exemplifico por meio de (61) e (62) que constituem uma espécie de "par mínimo", se essas sentenças forem pronunciadas hoje (1997):

(61) Durante anos a fio, Cid Moreira tem apresentado / apresentou o Jornal da TV Globo.

(62) Durante anos a fio, Eron Domingues *tem apresentado aos ouvintes da Rádio Tupi o Repórter Esso.

(63) Durante anos a fio, Eron Domingues apresentou aos ouvintes da Rádio Tupi o Repórter Esso.

O que causa a agramaticalidade de (62) é que o Repórter Esso, um jornal televisivo que ficou no ar com muito sucesso nas décadas de 50 e 60, já não 
existe. Se essa explicação é correta, o PASSADO COMPOSTO português obedece a uma restrição que afeta seu análogo inglês: informa que o fato relatado poderia estar acontecendo no momento de fala. Mc Cawley (1971) comenta esse fato para o inglês, retomando uma observação de Leech, e mostrando que a pergunta

(64) Have you visited the exhibition?

só é cabível se a possibilidade da visita se mantém. Se a exposição já terminou, ou se o interlocutor sofreu um acidente que o imobiliza, impedindo em caráter definitivo que ele faça a visita, a pergunta tem que ser formulada no SIMPLE PAST.

\section{PC assume eventualmente um valor de continuidade:}

Todos os exemplos até aqui apresentam o passado composto como um tempo que indica repetição, confirmando a análise de Gonçalves Viana. Já citei, entretanto, a opinião de Paiva Boléo para quem há ocorrências do PASSADO COMPOsто que exprimem uma idéia de duração. Os exemplos de Boléo são

(65) Tenho estado doente.

(66) À sombra do lindo céu

Jurei, tenho jurado

Não ter outros amores

Só a ti tenho amado.

e sugerem que o PASSADO COMPOSTO assume sentido durativo quando se aplica a um predicado cujo esquema aspectual envolve duração (segundo a classificação de Vendler, é o caso dos "states" como amar e das "activities" como empurrar um carrinho), mas essa é, na melhor das hipóteses, uma aproximação grosseira.

À primeira vista, os exemplos

(67) O doente tem ficado em seu quarto.

(68) O alarme tem ficado ligado.

(69) A porta central da basílica tem ficado fechada. 
qualificam um estado ou processo como permanente a partir de um determinado momento e, como não envolvem repetição em nenhum sentido óbvio, poderiam ser qualificados como permanentemente durativos. Não nego que essa interpretação seja possível, mas tenho dúvidas de que seja determinada exclusivamente pelo PASSADO COMPOSTO. Com efeito, pequenas modificações no vocabulário e um contexto apropriado, chamam novamente em causa a idéia de repetição: considerem-se, a propósito, as sentenças (70) - (72):

(70) O menino tem ficado em seu quarto.

(71) A televisão tem ficado ligada.

(72) A janela tem ficado aberta.

Elas poderiam indicar que o menino fica no quarto em todas as ocasiões em que seria esperada sua participação na rotina familiar, que a televisão fica ligada sempre que a última pessoa se deita ou que a janela fica aberta cada vez que as pessoas saem de casa para o trabalho ("sempre" = em todas as situações relevantes, que podem ser, por exemplo, todas aquelas que envolvem algum tipo de tensão). Um teste possível para confirmar a repetição é o acréscimo do adjunto "todas as vezes". Os três exemplos acima o aceitam, mostrando que essas sentenças podem indicar a repetição de pequenas durações. Teríamos que opor as representações (73) e (74), optando pela segunda:

(73) duratividade absoluta

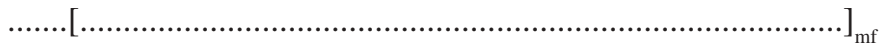

(74) duratividade intermitente

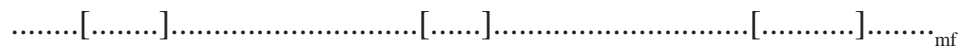

Em suma, a interpretação durativa das sentenças de state e activity é no máximo uma tendência, que resulta bloqueada por fatores que conhecemos mal: um desses fatores, conforme sugeri, é a existência de momentos de verificação pragmaticamente significativos: assim as três sentenças (75) a (77) poderiam estar relatando o que ocorreu em sucessivos balancetes, sucessivas decisões da nova diretoria ou sucessivas medições da temperatura.

(75) O cliente tem mantido um saldo em conta superior a 20.000 reais. 
(76) Tenho-me calado apesar de discordar das decisões da nova administração.

(77) A temperatura da terra tem subido desde que a humanidade começou a ter registros meteorológicos.

Outro fator que bloqueia a tendência a interpretar durativamente os passados compostos de verbos de state e activity é que o PASSADO COMPOSTO precisa às vezes ser referido a um tempo presente que já não é activity ou state. Assim, (78) é mais provavelmente o PASSADO COMPOSTO de (79) que de (80)

(78) O chefe da divisão de águas tem sido estúpido/inconveniente com as funcionárias.

(79) O chefe da divisão de águas está sendo estúpido/inconveniente com as funcionárias.

(80) O chefe da divisão de águas é estúpido / inconveniente com as funcionárias.

Outro fator é o uso dos sintagmas nominais em nível de stage, kind, etc. (no sentido de Carlson): é evidente que (81) se torna agramatical se o chefe da repartição identifica um indivíduo particular, e que a interpretação é forçosamente iterativa se for praxe substituir periodicamente o chefe

(81) O chefe da divisão de águas tem sido um funcionário de carreira e não um político.

Um último fator é a quantificação dos sintagmas nominais que acompanham o próprio verbo: a escolha do singular ou do plural para o substantivo controvérsia no espaço aberto de (82)

(82) A Alsácia e a Lorena têm sido motivo de entre a França e a Alemanha.

leva a pensar numa única pendência não resolvida, ou numa série de sucessivos atritos. Na forma de um estado de coisas persistente, ou de eventos episódicos, reencontramos aqui a distinção entre iteração e duratividade. 


\section{O passado composto: é possível um tratamento unificado?}

Pensando na segurança com que Gonçalves Viana qualificou o PASSADO COMPOSTo de "passé répétitif", e na igual segurança com que Boléo apontou para essa forma um valor durativo, é tentador perguntar se seria possível dar à semântica do PASSADO COMPOSTO um tratamento unificado. Os fatos levantados e as próprias indicações daqueles autores apontam para duas possíveis respostas, que tentarei formular explicitamente, menos para encaminhar uma escolha, do que para deixar claros os problemas que seriam preciso superar.

\section{A duração como paradigma}

Na primeira dessas linhas, tenta-se a caracterização unitária do passado composto dando realce a seu caráter durativo. Essa orientação se traduz em duas condições, das quais tudo mais precisará ser derivado:

a) o PASSADO COMPOSTO faz necessariamente referência a um período;

b) nesse período alguma coisa dura.

Se nos perguntarmos o que dura no intervalo, a resposta é imediata para muitas sentenças com predicados de state e activity: esses predicados fazem uma afirmação que é verdadeira para todos os momentos do intervalo, o que resulta numa interpretação durativa. As coisas se complicam, como vimos, com as sentenças de achievement ou accomplishment.

Uma manobra para incorporar esses casos consiste em admitir que tanto a repetição quanto a duração são manifestações de algum processo mais genérico e abstrato, a ser melhor caracterizado, que dura no período em questão. Poder-se-ia definir esse processo utilizando a relação "ser característico de", estabelecendo que um estado ou activity é característico de um intervalo quando sua duração cobre o intervalo; e que um accomplishment ou achievement é característico de um intervalo quando se repete nele com escalonamento no tempo. A idéia de que uma ação "pontual" possa caracterizar um intervalo não é um artifício ad hoc para dar conta do PASSADO COMPOSTO; na realidade toda vez que um predicado pontual esbarra num adjunto durativo, ou se combina com uma forma durativa (presente, imperfeito...) a repetição é disparada. 
(83) Nesse filme antigo, há uma cena de tiroteio em que os bandidos atiram nos mocinhos, e vice-versa, do $34^{\circ}$ ao $38^{\circ}$ minuto sem que caia nenhum chapéu.

(84) As guias do INAMPS foram mandadas para Brasília de 1964 a 1977. (iterativo)

Tem sido comum tratar os adjuntos de tempo como indicadores do momento de referência de um predicado - esse seria verdadeiro numa perspectiva definida a partir do momento indicado pelo adjunto. A proposta acima obriga a substituir "verdadeiro" por "característico" na definição do período de apuração. Afora essa conseqüência, a proposta equivale a aceitar a hipótese de que o PASSADO COMPOSTO afeta a interpretação do predicado a que se aplica, exatamente como a presença explícita de um adjunto de duração o faria, e de que tenho telefonado exprime uma ação complexa, que resulta da repetição de telefonemas individuais, da mesma forma que, segundo Vendler (1967), a ação de reinar seria o resultado da repetição, em intervalos variados, de ações particulares (como abrir a sessão corrente do Parlamento, participar de determinadas reuniões do Conselho de Estado, inaugurar esta ou aquela feira eqüina, etc.). Essa hipótese não explica por que

(85) O diretor da divisão de águas tem sido um funcionário de carreira.

sai agramatical, na hipótese de a divisão de águas ter tido até hoje um único diretor.

\section{A repetição como paradigma}

Numa linha de reflexão oposta, que talvez recupere a idéia de Gonçalves Viana, podemos tentar entender o PASSADO COMPOSTO como um tempo que remete a uma pluralidade de eventos passados do mesmo tipo. Podemos desdobrar essa tese nas duas condições seguintes:

a) O PASSADO COMPOSTO identifica uma certa proposição

b) Essa proposição se realiza em vários momentos do passado: ocorrem sucessivamente no passado fatos distintos, cada um dos quais torna verdadeira a proposição em questão. 
O passado não é, evidentemente, um passado indeterminado, mas um intervalo tal como foi caracterizado anteriormente; dadas essas condições, trata-se de reconstituir cada uso do passado composto como a indicação dos momentos em que a proposição por ele identificada será verdadeira. Ora, essa manobra também é problemática: sentenças como "José tem tido problemas de saúde" servem para assertar a existência de momentos (ou intervalos) sucessivos em que "José tem um problema de saúde". Mas o que asserta-se nas sentenças negativas correspondentes não é nem que há uma série de momentos (ou intervalos) em que José não tem problemas de saúde (se assim fosse, poder-seia afirmar sem contradição que José tem tido problemas de saúde no mesmo período em que não os tem tido, o que não é o caso), nem que inexiste uma repetição de situações em que José teve problemas de saúde (se fosse essa a informação veiculada pela sentença negativa, seria possível afirmar sem contradição que José não tem tido problemas de saúde desde que mudou para Campinas, mas os teve uma ou duas vezes nesse mesmo período, o que não é o caso)

As duas estratégias de tratamento unificado que consistem em absorver as interpretações durativas nas iterativas, ou vice-versa, levam a um impasse. Existe um tertius?

\section{Uma saída possível sem abdicar de um tratamento composicional}

Se, como venho afirmando, a escolha por uma interpretação durativa ou iterativa do PASSADO COMPOSTO é afetada pelas características de Aktionsart do predicado, seria desejável poder dispor de uma regra semântica única, que resultasse nas interpretações apropriadas, quando aplicada a diferentes configurações aspectuais. O dispositivo fundamental nessas tentativas de formalização é o mesmo de toda semântica que adota o princípio da composicionalidade, a saber, o dispositivo da função. Da mesma forma que, no domínio dos números, a função “...é o dobro de..." resulta em 6 quando aplicada a 3 e em 14 quando aplicada a 7, trata-se de descrever a perífrase de PASSADO COMPOSTO como uma função que resulta em valores semânticos diferentes, conforme o tipo de predicados a que é aplicada; é claro que, em vista disso, será preciso formular esses predicado de modo tal que a função "PASSADO COMPOSTO" possa operar sobre as características que são realmente relevantes.

Para tratar do PASSADO COMPOSTO nessa perspectiva unificada, a regra semântica precisa aplicar-se tanto a grandezas discretas como a grandezas contí- 
nuas, ou seja, ao invés de tentar reduzir a duração à iteratividade de eventos momentâneos, ou vice-versa, precisamos buscar uma matriz capaz de aceitar os dois tipos de eventos. Essa matriz não foi ainda plenamente formulada, mas a necessidade de lidar da mesma forma com o discreto e com o contínuo aponta para a pesquisa uma direção muito precisa. Há, em português, alguns quantificadores, muito, pouco, mais, menos, uma porção de etc., que resultam em interpretações diferentes conforme são aplicados a nomes comuns contáveis ou a termos de massa. Mais livros compara quantidades descontínuas (no sentido de conjuntos de objetos com cardinalidade maior ou menor); mais açúcar estabelece uma comparação entre quantidades de uma substância contínua. Parece-me significativo que haja quantificadores que transitam livremente entre nomes contáveis e não contáveis, um fato a que a literatura lingüística tem dado alguma atenção, mostrando - o que é essencial aqui - que o quantificador é $o$ mesmo nos dois usos (ver, por exemplo, McCawley, (1981)). Por analogia com esses quantificadores, o PASSADO COMPOSTO poderia também ser encarado como um "quantificador que transita" entre discretos e massivos, o que sugere que se apliquem a essa forma verbal as soluções encontradas para mostrar a dupla interpretação daqueles quantificadores. Convém então dar atenção à semântica de um tipo de nomes - os "massivos" - que têm sido tradicionalmente encarados pelas gramáticas como menos fundamentais.

Por sorte, há sobre esse tema uma bibliografia recente, a que serve de introdução em língua portuguesa um excelente trabalho de Maria do Céu Novais (1992), onde se retomam os principais tratamentos, e se elabora a comparação dos nomes contáveis e massivos sob o ponto de vista sintático, ontológico, semântico e técnico. Alguns exemplos analisados por Novais

(86) Esta salada tem muita cebola / tem duas cebolas.

(87) O peixe é um alimento muito saudável.

(88) Ao jantar comemos peixe.

(89) Alguns peixes só se pescam no alto mar.

levam a considerar a referência massiva ou contável como uma característica não dos substantivos enquanto entidades lexicais, mas do contexto oracional em que eles ocorrem. Novais (1992) mostra que os principais autores que lançaram o tema das relações entre nomes contáveis e massivos utilizaram, para 
fins de interpretação, um cálculo baseado na teoria dos conjuntos, e expõe com particular clareza o princípio por meio do qual um desses autores, Link (1983), procura mostrar que a assimilação dos massivos aos contáveis é intuitivamente correta.

Esse princípio é o chamado "princípio de referência cumulativa" e permite assimilar os massivos aos plurais, a partir do paralelismo entre, por exemplo, (90) e (91):

(90) If $\mathrm{a}$ is water and $\mathrm{b}$ is water, then the sum of $\mathrm{a}$ and $\mathrm{b}$ is water.

(91) If the animals in this camp are horses and the animals in that camp are horses, then the animals in both camps are horses.

O acréscimo de uma porção de água a algo que já era água resulta ainda em água, da mesma forma que o acréscimo de um ou mais cavalos a um conjunto de cavalos resulta ainda em cavalos. Em outras palavras, os nomes massivos e os plurais reagem igualmente à soma, apresentando uma propriedade de fechamento. Em termos matemáticos, esse fechamento transforma o universo de discurso em uma estrutura booleana, e permite que a extensão dos predicados que se definem sobre esse universo seja representada por meio de reticulados. Pode estar aqui, em seu cerne, o tertius que procuramos.

Não seria possível dizer mais sobre essa possível "solução" sem entrar numa exposição altamente técnica, por isso convém terminar. Várias vezes, ao tratar do PASSADO COMPOSTO português, vi-me em situações de impasse que evocavam o verso do poeta Carlos Drummond de Andrade "No meio do caminho tinha uma pedra". Ao encerrar este texto com a sugestão de investigar a bibliografia sobre plurais e massivos, outro capítulo extremamente complicado da semântica das línguas naturais, parece que o ganho não foi grande, como se, afinal, eu tivesse chegado ao verso drummondiano imediatamente seguinte: "Tinha uma pedra no meio do caminho.". Há certamente muito de "gauche" nisso. Espero entretanto que as reflexões feitas tenham contribuído para um balanço dos problemas com que um tratamento formal terá que haver-se. Há pedras e pedras, e gostaria de ter convencido meus leitores de que o PASSADO composto era, desde o início, uma pedra na qual vale a pena esbarrar. 


\title{
RESUMO
}

Neste texto, trato do pretérito (ou passado) composto do português, e procuro dar conta de alguns valores que o distinguem, no paradigma de conjugação. À diferença do infinitivo pessoal e do subjuntivo futuro, o PASSADO COMPOSTO existe em todas as línguas românicas que conheço; sua singularidade em relação a essas outras línguas, não diz respeito à forma, mas ao sentido; por conseguinte, este texto terá um enfoque semântico e tentará expor alguns dos problemas que encontrei, ao tentar propor para esse tempo composto uma definição semântica mais rigorosa.

Palavras-chave: Semântica formal, eventos, passado composto.

\begin{abstract}
This paper deals with the PASSADO COMPOSTO in Brazilian Portuguese, aiming at characterizing the semantic values that distinguish it from other verbal tenses. Different from the personal infinitive and subjunctive future, the PASSADO COMPOSTO exists in all romance languages; its singularity in BP with respect to other romance languages does not concern its form, but rather its meaning. Thus, this paper will focus on its semantic idiosyncrasy and will expose some of the problems found in the search for a more rigorous semantic treatment of such a composed tense.
\end{abstract}

Key-words: Formal semantics, events, passado composto.

\section{REFERÊNCIAS}

BOLÉO, M. de P. O pretérito e o perfeito em português, em confronto com as outras línguas românicas. Coimbra: Imprensa da Universidade, 1937.

BUNT, H. C. Mass terms and model-theoretic semantics. Cambridge: Cambridge University Press, 1985. 
ILARI, R. Notas sobre o passado composto em português

DAVIDSON, D. The logical form of action sentences. In: RESCHER (Ed.). The logics of decision and action. Pittsburgh: Pittsburgh University Press, 1967.

DOWTY, D. World meaning and Montague grammar semantics. Dordrecht: Reidel, 1979.

DOWTY, D; WALL, R.; PETERS, S. Introduction to Montague semantics. Dordrecht: Reidel, 1981.

ILARI, R.; GODOI, E; OLIVEIRA, P. de O. Delocutivos nós também temos, falô? Cadernos de Estudos Lingüísticos, Universidade Estadual de Campinas, n. 10, p. 81-86. 1986.

LINK, G. The logical analysis of plurals and mass terms: a lattice-theoretical approach. In: BAUERLE, R., SCHWARZE, C.; VON STECHOW (Ed.). Meaning, use, and interpretation of language. Berlim: W. de Gruyter, 1983. p. 302-322, 1983.

MCCAWLEY, J. D. Everything that linguists have always wanted to know about logic, but they were ashamed to ask. Chicago: Chicago University Press, 1981.

MEULEN, A. Substances, quantities and individuals - A study in the formal semantics of mass terms. Bloomington: Indiana University Linguistic Club, 1980.

MONTAGUE, R. The proper treatment of quantification in english. In: THOMASON, R. (Org.). Formal philosophy. Selected papers of Richard Montague. Yale: Yale University Press, p. 247-269, 1974.

MORGADO, J. Introdução à teoria dos reticulados. Boletins do Instituto de Física e Matemática da Universidade do Recife, n. 10-11, 1962. 2 v.

NOVAIS, M. do C. Aspectos da referência massiva . Cadernos de Semântica, Lisboa, n. 3, 1992. Projecto JNICT-PCSH/C/LIN/212/91, Faculdade de Letras da Universidade de Lisboa.

VENDLER, Z. Linguistics and philosophy. Ithaca: Cornell University Press, 1967.

VIANA, A. R. G. Le portugais: phonétique et phonologie, morphologie, textes. Leipzig: Teubner, 1901. 